Doi: http://dx.doi.org/10.5212/OIharProfr.v.12i1.181191

\title{
PRACTICE MAKES PERFECTION - UMA REFLEXÃO SOBRE EXPECTATIVAS NO CURSO DE FORMAÇÃO DE PROFESSORES DE LÍNGUA INGLESA \\ PRACTICE MAKES PERFECTION - EXPECTATIONS ABOUT ENGLISH TEACHER EDUCATION
}

\author{
Michele Andreza Teixeira PASSINI * \\ Thaísa de Andrade JAMOUSSI ${ }^{* *}$
}

Resumo: O presente artigo apresenta uma visão geral dos cursos de formação inicial de professores de Inglês e dos documentos que norteiam esse nível de formação no Brasil. Especial atenção é dada ao perfil, competências e habilidades esperadas dos futuros professores de Inglês. A pesquisa adotou uma abordagem qualitativa e incluiu a implementação de um projeto de extensão e coleta de dados por meio de um questionário aberto. $\mathrm{O}$ projeto de extensão tinha por objetivo contribuir para o aprimoramento das habilidades linguísticas dos futuros professores de Inglês e de professores de Inglês em serviço, além de servir como um fórum de discussão e reflexão. A análise dos dados aponta para a preocupação dos futuros professores e dos professores em serviço a respeito dos seguintes aspectos: o interesse em desenvolver competências linguísticas e comunicativas, em vez de um interesse pelas competências e habilidades necessárias para o ensino da língua estrangeira; o interesse pela habilitação simples e não pela dupla habilitação, como acontece na maioria dos cursos de formação inicial, isto é, Português e uma Língua Estrangeira. Os resultados sugerem a necessidade de conscientização a respeito

* Licenciada em Letras pela UEPG. E-mail: michele.at@gmail.com

** Mestre em Letras pela UFPR. E-mail: thaisadeandrade@yahoo.com 
Practice makes perfection - uma reflexão sobre expectativas...

do papel e dos objetivos dos cursos de formação inicial por parte dos interessados em se tornarem professores, para que estes saibam o que esperar dos cursos e para que também saibam qual o seu papel no processo de sua formação.

Palavras-chave: Língua Inglesa. Proficiência. Formação de professores.

Abstract: This article presents an overview of initial English language teacher education and the official documents that guide this level of education in Brazil. Special attention is given to the profile, competences and skills expected from future English teachers. The study adopted a qualitative approach which involved the implementation of an outreach project and the use of an open questionnaire for data collection. The outreach project aimed at improving future and in-service English teachers as well as to provide a forum for discussion and reflection. The data analysis point out future and in-service English teachers' concern about aspects such as: their interest in linguistic and communicative competences instead of an interest in the competences and skills necessary for the teaching of the language; their interest in obtaining a degree only in English and not a double degree as is the case in most initial education courses, that is, Portuguese and a foreign language. The outcomes suggest a need for an awareness about the role and aim of initial English education courses from those interested in becoming teachers so that they know what to expect from the courses as well as their role in the process.

Keywords: English. Proficiency. Teacher Education. 


\section{INTRODUÇÃO}

A preocupação com a formação inicial de professores vem sendo uma constante no âmbito educacional, a ponto de já há muito tempo ter se tornado um problema governamental e objeto de estudo de diferentes pesquisas, como aponta Piconez (2001). O número crescente de estudos sobre a formação de professores de línguas também comprova a inquietação de pesquisadores da área de Educação em entender como os futuros profissionais estão sendo preparados.

Diante disso, é fundamental a reflexão, no quadro da língua estrangeira, de duas questões principais: a proficiência no idioma e a didática para ensiná-lo. Barcellos (2004) ressalta a importância de tais conhecimentos como saberes que devem fazer parte do profissional.

Os cursos de formação de professores pautam-se na legislação atual das Diretrizes Curriculares Nacionais para formação de professores (Resolução CNE/CP 1, de 18 de fevereiro de 2002), a qual estabelece, dentre outras questões, a consideração do conjunto de competências necessárias à atuação profissional, bem como a adoção dessas competências como norteadoras tanto da proposta pedagógi$\mathrm{ca}$, em especial do currículo e da avaliação, quanto da organização institucional e da gestão da escola de formação.

\section{O QUE SE ENTENDE POR COMPETÊNCIA}

É possível notar que o termo competência é recorrente tanto na literatura de Linguística aplicada, quanto nos documentos oficiais citados acima. Portanto, é de grande importância saber o que se entende por competência.

Se for tomada como referência à teoria descrita pelo linguista norte-americano Noam Chomsky, no final da década de 50, competência é entendida como "o conhecimento mental puro de uma língua particular por parte do sujeito falante, isto é, sua gramática interiorizada", sendo contraposta ao conceito de performance (ou desempenho), que designa o uso concreto da linguagem em situações de fala concretas. (CHOMSKY, 1965 apud RAPOSO, 1992).

Há ainda diferentes conceitos de competência, como os que Almeida Filho (2001) menciona. O autor enfatiza cinco competências fundamentais para um professor de língua comunicativo. São elas: 
Practice makes perfection - uma reflexão sobre expectativas...

- Competência implícita: desenvolvida a partir das experiências de aprender língua(s) que vivemos;

- Competência teórica: corpo de conhecimentos que podemos enunciar;

- Competência aplicada: capacidade de ensinar baseada na competência teórica adquirida;

- Competência linguístico-comunicativa: conhecimento linguístico que se dispõe e se é capaz de concretizar;

- Competência profissional: reconhecimento do valor de ser professor de língua, responsabilidade pelo próprio desenvolvimento profissional e dos outros e as ações correspondentes.

Ao se comparar o conceito de competência de Chomsky aos cinco tipos mencionados por Almeida Filho, é possível notar que ocorre uma bipartição do primeiro em competência implícita e competência linguístico-comunicativa.

Ao se pensar um professor de Língua Estrangeira em formação, com base nas Diretrizes Curriculares Nacionais, as competências implícita e linguístico-comunicativa seriam consideradas como previamente adquiridas, e as competências teórica, aplicada e profissional, seriam aquelas a serem desenvolvidas no decorrer do curso.

Entretanto, o que se observa é uma divergência de expectativas por parte de acadêmicos que, ao ingressarem no curso de Letras, buscam, principalmente, as duas primeiras competências, pressupostas pelos documentos oficiais, e, portanto, pela instituição, como já existentes.

Com base na matriz curricular apresentada nas Diretrizes Curriculares Nacionais (CNE/CP1 de 18 de fevereiro de 2002), cada instituição desenvolve um projeto pedagógico para o curso de formação de docentes.

Ao se analisar os documentos do curso de Licenciatura em Letras de uma universidade estadual do sul do Brasil, encontram-se as seguintes habilidades básicas como pertencentes ao profissional formado pela instituição:

- Ler, compreender e analisar o uso da Língua Portuguesa e da Língua Inglesa nas suas manifestações oral e escrita culta;

- Analisar as características de proximidade e afastamento em relação à gramática normativa;

- Descrever e justificar as características fonológicas, morfológicas, 
lexicais, sintáticas, semânticas e pragmáticas de variedades da Língua Portuguesa e Inglesa, em diferentes contextos;

- Compreender, à luz das diferentes teorias, os fatos linguísticos e literários e conduzir investigações sobre linguagem e sobre problemas relacionados ao ensino aprendizagem de línguas e de literatura;

- Ler e analisar criticamente textos literários e identificar relações de intertextualidade entre obras da literatura em Língua Portuguesa e da Literatura Universal;

- Relacionar o texto literário com os problemas e concepções dominantes na cultura do período em que foi escrito e com os problemas e concepções do presente;

- Compreender e aplicar diferentes teorias e métodos de ensino que permitam a transposição didática dos conhecimentos sobre língua e literatura para o ensino Fundamental e Médio.

Como é possível observar, o desenvolvimento da competência linguístico-comunicativa do acadêmico é apenas um dos itens dentre tantos outros a serem desenvolvidos nos futuros profissionais formados pela referida instituição.

A questão da expectativa dos acadêmicos quanto ao que o curso proporcionaria a eles foi refletida no contexto de um projeto de extensão realizado na instituição.

\section{O PROJETO DE EXTENSÃO PRACTICE MAKES PERFECTION}

Observou-se uma preocupação recorrente dos acadêmicos de Letras da referida universidade quanto ao nível insatisfatório de proficiência na Língua Estrangeira e o limitado espaço para prática oral e escrita, atribuídos principalmente à baixa carga horária de aulas de Língua Estrangeira no decorrer do curso.

O projeto nasceu, portanto, da necessidade de um espaço onde fosse possível praticar a Língua Inglesa, buscando aprimorar a fluência na língua, bem como discutir e compartilhar questões comuns aos acadêmicos de Letras, habilitação Português/Inglês, e profissionais atuantes como professores de Inglês da rede pública.

Dentre os doze participantes do projeto de extensão, seis eram professores de Inglês de Ensino Médio e Fundamental há mais de dez anos, enquanto os outros seis eram acadêmicos do curso de Letras. 
Practice makes perfection - uma reflexão sobre expectativas...

O projeto teve frequência mensal, totalizando 30 horas de atividades interativas, voltadas principalmente à prática da oralidade.

No primeiro encontro, a questão das aulas de Língua Inglesa realizadas no curso de Letras, Habilitação Inglês/Português, foi discutida pelos participantes, gerando opiniões divergentes. Dentre as opiniões, de um lado pronunciavam-se os que acreditavam que as aulas eram avançadas demais e, por isso, não eficientes, já que exigiam um conhecimento prévio do idioma. De outro lado, apresentavam-se aqueles que esperavam um nível mais desafiador das aulas e as classificavam como "fracas". A partir dessa polêmica, uma pesquisa qualitativa foi realizada a fim de ouvir a voz dos participantes quanto às suas aulas de Língua Inglesa na universidade, assim como para investigar suas expectativas quanto à referida língua no curso de graduação.

O ponto norteador da pesquisa foi contrapor os objetivos dos ingressantes no curso de Licenciatura de Letras Inglês com os objetivos da instituição de ensino superior.

\section{OUVINDO OS INTERESSADOS}

A abordagem de investigação adotada foi do tipo qualitativa, na qual, segundo Goldenberg (2007), "a preocupação do pesquisador não é com a representatividade numérica, mas com o aprofundamento da compreensão de um grupo social, de uma organização, de uma instituição, etc". Neste contexto, a escolha desta abordagem justifica-se por permitir a compreensão dos modos como os informantes entendem as questões relacionadas às aulas de Língua Inglesa realizadas na instituição de ensino. Isto é, possibilita a explicitação das dimensões das respostas dadas, já que as perguntas são abertas, levando o informante a expressar-se subjetivamente. Ademais, esse nível de estudo permite a realização de orientações diferenciadas na abordagem do problema, pois, segundo Bogdan e Biklen (1994), a abordagem qualitativa assume muitas formas e é conduzida em múltiplos contextos.

Através de um questionário, composto por seis perguntas, os informantes foram convidados a responder: (1) o que os motivou a cursar Licenciatura em Letras Português/Inglês; (2) seu conhecimento prévio ao ingressar no curso; (3) expectativas em relação às aulas de Língua Inglesa; (4) se a expectativa foi, ou não, correspondida e por quê?; (5) o que poderia ser reformulado nas aulas de Inglês; (6) 
segurança quanto à competência linguística ao final da formação. Tais perguntas foram elaboradas com base em discussões levantadas pelos participantes nos encontros do projeto de extensão. O questionário foi aplicado aos participantes do projeto em um dos encontros mensais.

\section{COMENTÁRIOS TECIDOS PELOS INFORMANTES}

Algumas respostas da primeira questão ( $\mathrm{O}$ que o motivou a cursar Licenciatura em Letras Português/Inglês?) retiradas dos questionários respondidos, informam:

(1) O fato de sempre ter gostado de estudar inglês, associado ao fato de não poder fazer um curso diurno devido ao trabalho.

(2) A princípio comecei a estudar inglês por imposição da grade, éramos obrigados a fazer Português e Inglês. Não havia opção, caso contrário não teria feito.

(3) Literatura Inglesa e Inglês para uso próprio.

Nas respostas fornecidas, é possível perceber que os motivos para cursar Licenciatura em Letras Inglês/Português foram bastante diversificados. Acima, em (1) observa-se que a motivação vem da afinidade com a Língua Inglesa, aliada a uma impossibilidade de estudar a língua de outra forma, em um curso de idiomas, por exemplo. Já em (2) o fato de a instituição oferecer apenas dupla habilitação, isto é, Português e Inglês simultaneamente, constitui um problema para o informante, uma vez que seu interesse foi apenas a Língua Portuguesa. O informante em (3) afirma que foi motivado a ingressar no curso para usar os conhecimentos da Língua Estrangeira em benefício próprio, e não para atuar como professor, mesmo que o curso seja uma licenciatura.

Na segunda questão (qual era o seu conhecimento prévio ao ingressar no curso?), seis dos informantes classificaram seus conhecimentos na língua como sendo "básicos", somente o que aprenderam nas aulas no decorrer do Ensino Médio. Quatro afirmaram ter ingressado com conhecimentos "intermediários", enquanto dois informantes consideram que já tinham nível "avançado" de proficiência na língua estrangeira. ${ }^{1}$

\footnotetext{
${ }^{1}$ Não fez parte do escopo da pesquisa discutir os conceitos de níveis de proficiência (básico, intermediário e avançado) em Língua Estrangeira.
} 
Practice makes perfection - uma reflexão sobre expectativas...

Como já mencionado, as aulas de Língua Inglesa, no decorrer do curso de graduação, geraram opiniões divergentes já no primeiro encontro do grupo. Na questão em que eram convidados a expressar-se acerca deste assunto, o grupo dividiu-se em satisfeitos e insatisfeitos com as aulas. Abaixo respostas de informantes que não tiveram suas expectativas correspondidas nas aulas ministradas no decorrer do curso:

(4) Os professores na época, somente estavam preocupados em cumprir o programa e não em trabalhar com as dificuldades de seus alunos (superá-las).

(5) Porque o estudo na língua começa na universidade pelo nível básico, muitos alunos não têm nenhum conhecimento, não se esforçam para buscar este conhecimento e acabam não sendo cobrados por isso.

(6) As aulas sempre foram voltadas mais à gramática. Os professores não trabalham bem a oralidade.

(7) Os professores esperavam de nós um nível que não tínhamos (90\% da turma), e davam suas aulas supondo que sabíamos muito, tenho a impressão que lecionavam apenas para os $10 \%$ que tiveram a oportunidade de ter um contato maior com a língua, o que não acontecia com grande parte de nossa turma.

(8) A transcrição fonética não tivemos e, acho que é a base para aprender a falar certas palauras.

Contrapondo a resposta em (5) com o que é afirmado em (7), pode-se perceber a heterogeneidade no nível de proficiência dos acadêmicos na Língua Estrangeira, e também como os objetivos de ensino da instituição não estão claros para os mesmos, uma vez que há os que se sentem excluídos por não conseguirem acompanhar as aulas (como em 7), e os que se sentem descontentes por considerarem que poderiam ir mais longe, não fosse a falta de esforço dos colegas (como em 5).

Dentre os dois informantes com expectativas correspondidas, encontram-se as justificativas abaixo:

(9) Naquela época os professores eram muito competentes e experientes. 
(10) Sim, em quatro anos eu aprendi muito e fui incentivada a estudar muito mais sempre.

Dentre as sugestões apresentadas quanto ao que poderia ser reformulado nas aulas de Língua Inglesa do curso, os informantes mencionaram uma possível classificação dos alunos em níveis de proficiência na Língua Estrangeira, ao ingressar no curso, e ainda que as turmas fossem menores:

As aulas de hoje estão mais voltadas a comunicação, mas em escola pública ou particular está se caminhando para isso, embora precise de material didático, principalmente escola pública.

Poderia ter um teste de proficiência que exigisse um conhecimento mínimo e os professores poderiam cobrar esse conhecimento. Em minha opinião, um curso universitário com habilitação em língua estrangeira deveria aperfeiçoar os conhecimentos e não ensinar a língua básica.

Trabalhar em classes menores.

Deveria se fazer uma pesquisa de nível no início das aulas, e a partir daí direcionar suas aulas, deve ser levado em conta os diferentes níveis e as diferentes oportunidades dos alunos. Embora meu inglês não fosse "tão ruim" e dificilmente não soubesse o que meus alunos perguntavam, (pois lecionava para $5^{\circ}$ séries), acho muito complicado dizer "sou professor de inglês" e não ter um nível, no mínimo, razoável.

Mais conversação, gírias e expressões.

Como é possível perceber, as respostas fornecidas pelos participantes do projeto de extensão demonstram que suas expectativas são relacionadas, principalmente, a adquirir competência implícita e linguístico-comunicativa na Língua Estrangeira.

Um fato interessante e que deve ser considerado dentre as respostas é o de nenhum deles ter citado o desejo de se tornar professor de Língua Inglesa ou mesmo Portuguesa. Essa questão liga-se ao fato de as suas expectativas estarem voltadas mais para o desenvolvimento da competência linguística que para a aprendizagem de questões metodológicas nas aulas. Há uma grande divergência de opiniões quanto ao nível das aulas de língua. É possível perceber que as opiniões dividem-se, principalmente em participantes que ainda estão frequentando o curso e professores já formados há mais 
Practice makes perfection - uma reflexão sobre expectativas...

de dez anos. Os primeiros relatam que esperavam desafios maiores das aulas de Língua Inglesa, enquanto os segundos reclamam que as aulas não correspondiam ao conhecimento que os alunos tinham. Embora motivados por diferentes fatores, ambos os grupos (graduandos e graduados) mencionaram a necessidade de um exame prévio na disciplina de Língua Inglesa, por acreditarem que as classes são heterogêneas quanto ao nível de proficiência na língua, dificultando o seu ensino/aprendizado.

\section{CONSIDERAÇÕES FINAIS}

Os dados expostos neste artigo tiveram como intenção abordar uma questão constante no contexto de formação de professores, isto é, o que é responsabilidade da instituição que forma e o que é do futuro profissional.

Com base nas informações obtidas através da pesquisa realizada no projeto de extensão "Practice makes perfection", foi possível perceber que há acadêmicos que, ao ingressarem no curso de Licenciatura em Letras Português/ Inglês, buscam adquirir conhecimentos de língua, ou seja, competência implícita e linguístico-comunicativa, em vez de conhecimentos didáticos e metodológicos para a prática docente que os espera após o curso. Diante deste contexto, a falta de consciência acerca do que deve ser desenvolvido no curso de licenciatura em Letras costuma gerar insatisfação e mal-estar.

Outro ponto que merece atenção é a dupla habilitação, que, como abordado por um dos informantes na pesquisa, pode levar o aluno a cursar uma das disciplinas somente por não ter outra opção e não porque realmente quer seguir a profissão. Considera-se, no entanto, que não é o objetivo da instituição, com respaldo nas Diretrizes Curriculares Nacionais, desenvolver tais competências, e sim formar professores de língua, desenvolvendo as competências teóricas, aplicada e profissional.

É possível inferir que o que suscita essa insatisfação por parte dos graduandos e graduados que participaram da pesquisa é a lacuna existente entre suas expectativas ao ingressar no curso e os objetivos da instituição formadora de professores. Uma vez que seja claro o que esperar das aulas de Língua Inglesa na universidade, espaços poderiam ser abertos para que cada um tomasse sua parcela de responsabilidade e deixasse de se considerar vítima do processo. 
Michele Andreza T. PASSINI; Thaísa de Andrade JAMOUSSI

\section{REFERÊNCIAS}

ALMEIDA FILHO, J. C. P. de. Dimensões comunicativas no ensino de línguas. Campinas: Pontes, 1993.

ANDRADE, T. A metodologia e prática de ensino de inglês e a formação de professores. Dissertação de Mestrado. Curitiba: UFPR, 2000.

BOGDAN, R. C.; BILEN, S. K. Investigação qualitativa em educação. Porto, Portugal: Porto Editora, 1994.

GOLDENBERG, M. A arte de pesquisar: como fazer pesquisa qualitativa em Ciências Sociais. 10 a edição. Rio de Janeiro: Record, 2007.

MARGONARI, D.; SILVA, A. Forças atuantes no processo de formação de professores pré-serviço de língua inglesa.

NUNAN, D. Research methods in language learning. Cambridge: Cambridge University Press, 1995.

PICONEZ, S. B. A aproximação da realidade escolar e a prática da reflexão. In: PICONEZ, S.B. (Org.) A prática de ensino e o estágio supervisionado. Campinas: Papirus, 2001.

RAPOSO, E.P. Teoria da gramática: A faculdade da linguagem. Lisboa: Caminho, 1992.

Enviado em: 21/06/2009

Aceito em: 30/09/2009 